\title{
O uso da tecnologia digital como ferramenta facilitadora para o ensino de língua espanhola
}

\author{
The use of digital technology as a facilitating tool for spanish language teaching
}

Patrícia Keli Santos ${ }^{1}$

\begin{abstract}
Resumo
O presente artigo analisa pesquisas, sobre o uso das tecnologias digitais para o ensino de Língua Espanhola. Como aporte teórico para a escrita do texto, além das pesquisas revisadas, o presente artigo teve um embasamento teórico em Tesdesco (2012), Pierre Lévy (1999), Kenski (2012) e outros autores, que abordam questões sobre o ensino aprendizagem de Língua Espanhola e os avanços tecnológicos nas práticas pedagógicas. Tendo como relevância verificar como as tecnologias digitais estão sendo inseridas na escola. Com o intuito de refletir como os professores tem se apropriado das tecnologias digitais para o ensino de Língua Espanhola. A revisão literária dos artigos serviram para uma reflexão em torno dos desafios de ensinar a Língua Estrangeira (E/LE) utilizando a internet como recurso didático facilitador de experiências virtuais de imersão cultural. Conclui se que a inserção da tecnologia digital no espaço de ensino aprendizagem de Língua Espanhola, pode modificar a forma de práxis atual, para que a aprendizagem e aquisição de uma Língua Estrangeira seja algo interessante, eficiente e prazeroso
\end{abstract}

Palavras-chave: Tecnologias digitais; Espanhol; Aprendizagem.

\footnotetext{
${ }^{1}$ Mestra em Educação, Universidade Federal de Lavras UFLA-MG, Lavras, Minas Gerais, Brasil. E-mail: pattykeli@yahoo.com.br
} 


\begin{abstract}
This article analyzes research on the use of digital technologies for teaching Spanish. As a theoretical contribution to the writing of the text, in addition to the revised research, the present article had a theoretical basis in Tesdesco (2012), Pierre Lévy (1999), Kenki (2012), and other authors, who address questions about teaching Spanish language learning and technological advances in pedagogical practices. Having as relevance to verify how digital technologies are being inserted in the school. In order to reflect how teachers have appropriated digital technologies for the teaching of Spanish. The literary review of the articles served to reflect on the challenges of teaching the Foreign Language (E / LE) using the internet as a didactic resource that facilitates virtual experiences of cultural immersion. It is concluded that the insertion of digital technology in the Spanish language teaching and learning space, can modify the current praxis form, so that the learning and acquisition of a Foreign Language is something interesting, efficient and pleasurable.
\end{abstract}

Keywords: Digital technologies; Spanish; Learning.

\title{
Introdução
}

O presente artigo apresenta uma análise teórica sobre o uso das tecnologias digitais para o ensino de Língua Espanhola.

Diante das transformações tecnológicas o professor necessita de uma nova postura evidenciando a incorporação dos avanços tecnológicos nas práticas pedagógicas.

Atualmente, com a era da comunicação e informação, a realidade tecnológica sofreu uma grande mudança nas relações humanas e consequentemente nos processos de conhecimento refletindo também no processo educacional.

Percebe se que hoje o mundo está funcionando em rede, conforme destacam as Orientações Curriculares do Ensino Médio OCEM pode se notar que o pensamento simples do conhecimento já não é aceitável dentro das nossas relações sociais e culturais, em um contexto no qual os ambientes virtuais passam a coexistir com o ambiente presencial para o compartilhamento de ideias. Assim o papel do professor deve contemplar uma prática pedagógica multidimensional e dialógica utilizando a tecnologia digital a seu favor.

Nesse viés, o professor necessita ampliar sua formação para que as suas aulas não contemplem apenas os métodos tradicionais de ensino, mas também para que ele tenha sempre novos temas de acordo com as necessidades da sociedade e da comunidade, o que permite estimular os estudantes sempre em busca de uma educação libertadora. 
Dessa maneira para o educador, o recurso tecnológico aparece como um recurso inovador diante dos problemas detectados, como defict de aprendizagem, como um método de tentativa de sanar as lacunas do processo de ensino aprendizagem.

Diante do exposto, vale ressaltar que o professor e o estudante poderão obter um conhecimento intelectual necessário para entender o mundo atual, pois a tecnologia digital permite uma imersão de caráter virtual, que pode contribuir significativamente com o processo de ensino-aprendizagem de língua estrangeira, com ênfase na Língua Espanhola.

Nessa perspectiva a revisão literária dos artigos, e do referencial teórico, direcionam para uma reflexão em torno dos desafios de ensinar a Língua Estrangeira (E/LE) utilizando a internet como recurso didático facilitador de experiências virtuais de imersão cultural.

\section{Tecnologia digital como ferramenta de imersão virtual e cultural}

A internet atualmente aparece como recurso tecnológico que permite uma imersão de caráter virtual, ela pode incluir o indivíduo na cultura de um povo, podendo assim contribuir significativamente com o processo de ensino-aprendizagem de um estudante de Língua Estrangeira, que poderá assim, ter a oportunidade de chegar pela aplicação do recurso a lugares que oferecem condições de conhecer e explorar e vivenciar experiências em outro idioma sem nenhum tipo de fronteira geográfica.

Nessa perspectiva, o professor pode ter um livre acesso a informações para o desenvolvimento de competências que podem aproximar o estudante ao contato com a língua estrangeira, em questão Espanhol Língua Estrangeira (E/LE), permitindo assim a construção do conhecimento.

Nesse sentido Lévy (1999 p.15) afirma que "a Cibercultura expressa o surgimento de um novo universal, diferentes formas culturais que vieram antes dele no sentido de que se constrói sobre a indeterminação de um sentido global qualquer”. Precisamos de fato colocar o ensino de línguas dentro da perspectiva das mutações anteriores da comunicação.

A internet apresenta caminhos internacionais e culturais possibilitando uma proximidade maior. Com o seu uso, o ensino de língua espanhola que está tão recente nas escolas brasileiras, não se limita a educadores, estudantes e materiais didáticos impressos, mas sim a um mundo interativo, cheio de possibilidades. Como afirma Kenski: 
O ciberespaço abre novas possibilidades e configurações para as pessoas aprenderem. Dispostas, informais, com muita vontade de aprender o que lhes interessa, sem discriminações, sem deslocamentos físicos reunidas virtualmente em "comunidades virtuais", essas pessoas inauguram uma nova era para educação. (KENSKI 2012, p.102).

Nesse contexto, com a integração das tecnologias digitais no espaço escolar para o ensino de língua espanhola, abre possibilidades para o conhecimento do mundo fora da sala de aula. O que oferece insumo e imersão natural na língua e cultura dos países "hispanohablantes" criando assim oportunidades e desenvolvimento das habilidades de leitura, interpretação, escrita, compreensão oral e escrita.

Nessa perspectiva pode se destacar o "Ensino assistido por computador" significando que programa educacional ou opção educacional, que utiliza um conteúdo de ensino particular sobre os recursos de TI, processos ou atitudes. Se trata de uma aplicação educativa de informação e tecnologia de comunicações (TIC).

Com a crescente utilização das tecnologias digitais nas escolas, a especialidade é o ensino da rede baseada em linguagem (Internet, email, etc.). No campo específico do ensino E(LE), falando sobre o ensino da língua espanhola assistida por computador com o uso de equipamentos e software para auxiliar o professor, facilitando e complementando seu ensino para apresentar e explicar novos conteúdos, oferecendo possibilidades de prática linguística, incluindo os estudantes, avaliando, o interesse e as habilidades.

O ensino de Língua Espanhola assistido por computador mostra a aprendizagem de línguas em dois aspectos complementares de um mesmo fenômeno, a partir do primeiro professor óptico e o segundo a participação do aluno.

Llera y Sánchez (2003 p.36) "el verdadero secreto educativo de internet es la intencionalidad, la reflexión" desse modo as aplicações e variantes o uso do computador como instrumento básico ou usando como "enciclopédias e dicionários em revistas, etc", para complementar materiais mais tradicionais que desde o início incorporaram computadorInternet, multimídia, videoconferência, etc. E os seus instrumentos tecnológicos e tradicionais como o rádio, televisão, cassetes, são citados, todos esses artefatos tecnológicos envolvidos no desenvolvimento de tecnologias da linguagem em espanhol.

Programas (E/LE) em linha com as exigências do mundo globalizado, atualmente, exigem um processo de estruturação de aprendizagem espaços em pilares de linguística e 
cultural, isto é, temos de assegurar a intersecção aspectos linguísticos e socioculturais, quando se organiza um curso em uma língua estrangeira, especialmente quando se projetado para situações de imersão linguística e cultural. Mateo Martínez aponta que:

[...] cuestiones extralingüísticas como la gestualización o la proxémica [...] revisten una importancia crucial en el correcto devenir de la conversación ¿Y qué decir de otros aspectos socioculturales tan distintos entre las diferentes lenguas como el sentido del humor, la jerarquía social y sexual, los hábitos alimenticios, gustos y etiqueta social, etc., etc.? La enseñanza de idiomas traspasa así un umbral linguístico al abandonar el refugio gramatical y penetrar en el ámbito social, mucho más complejo y arbitrario, pero no menos necesario para el alumno. Debemos, pues, instruir a nuestros estudiantes en los asuntos típicamente lingüísticos del idioma sin olvidar que ésos habrán de manifestarse en un contexto social regido por sus propias reglas, que también es conveniente conocer. (MATEO MARTÍNEZ 1999 p.172).

Todavia a aprendizagem de uma língua estrangeira exige o desenvolvimento de habilidades diversas como a leitura, escrita, oralidade e audição. Essas habilidades e capacidades de comunicação podem ter uma prática eficaz aliada com a utilização do campo tecnológico virtual para as múltiplas interações para um aproveitamento e consolidação desse conteúdo, sendo que cada educador use essa tecnologia da forma que está ao alcance da escola.

Existem algumas dificuldades no ensino e aprendizagem de uma língua, principalmente a língua estrangeira, sobretudo em escolas públicas, devido a carga horária do conteúdo na grade curricular, os problemas de salas lotadas e infraestrutura, o que acaba ocasionando a repetição de métodos tradicionais, os professores ensinam uma língua sem que ocorra nenhuma uma reflexão.

Nesse viés, a tecnologia digital pode possibilitar que o docente consiga em sua própria prática refletir sobre a questão da importância de buscar identificar e analisar a sua prática pedagógica, com a intenção de contribuir assim, para a questão do ensino e aprendizagem de língua estrangeira, mediada por variadas tecnologias digitais de modo crítico e reflexivo.

\section{Conceitos para implicações na integração das tecnologias digitais para o ensino de língua espanhola}


Diante da globalização, e as transformações que ocorrem na sociedade, a formação do professor também precisa ser bem efetivada, uma vez que a função do educador também se amplia com a implicação da própria dimensão educacional do ensino que realiza.

Nesse contexto, a era da comunicação e informação, a realidade tecnológica atual, a educação, todos sofreram uma grande mudança nas relações humanas e consequentemente nos processos de conhecimento. Conforme Tedesco:

Cubrir ese déficit supone adoptar una posición ético- política en la corriente de aquellos que sostienen la idea de construir una sociedad más justa como ideal que puede y debe orientar el comportamiento de los actores sociales y, más específicamente, de los actores de los procesos educativos. La base de esta posición radica en reconocer que en la sociedad de la información y el conocimiento, una educación de calidad para todos es condición necesaria para el logro de la justicia social. (TEDESCO $2012 \mathrm{np}$.):

A constante presença das tecnologias digitais nas atividades socioculturais assumiu um papel importante na atualidade, com o uso dos computadores e celulares, TV, rádio entre outras tecnologias. Cabe ao educador promover a utilização desses meios de forma efetiva na educação. Sendo desafiador o acesso a essas tecnologias digitais em todas as escolas.

Além disso, (IEL-Interação 2009, p.13) relata que vários sites educacionais, já estão sendo aplicados na escola, as redes sociais também estão sendo um aporte para o ensino de línguas, como o facebook, livemocha, twitter entre outros, os aplicativos para celulares também têm sido muito utilizados, como whatsapp, duolingo, dicionários, ente outros.

Nessa direção, Almeida Filho (2009, p.123) menciona sobre "a dificuldade e complexidade do ensino e aprendizagem de uma língua, uma vez que, geralmente os métodos de ensino são apenas repetidos sem que haja uma reflexão". A maioria dos métodos tradicionais de ensino como escrita e tradução, muitas vezes são inseridos sem uma contextualização.

Desse modo, surge a necessidade de se do professor pensar em investir em uma formação que incitem a se constituir como profissional reflexivo, para que, de fato, possa 
contribuir para um ensino de línguas, notadamente, orientado por princípios textuais e discursivos, contemplando os diferentes usos da linguagem e a multiplicidade de contextos sociais.

Em suma, é possível constatar, que as transformações tecnológicas pelas quais os diversos setores da sociedade passaram exigem novas posturas do profissional da educação e da escola, evidenciando as necessidades da incorporação das tecnologias digitais, principalmente para o ensino de línguas, visto que as mídias podem ser um aparato tecnológico muito eficaz.

Sendo assim, de acordo com as premissas do PCN -LE ainda pode ser um desafio para o educador, deixando de vez a postura de transmissor do conhecimento, que ainda se percebe em alguns contextos, para assumir a postura de mediador e orientador das situações de aprendizagem, sabe se que a inclusão de tecnologias digitais por si só, não garantem a mudança do modelo pedagógico.

Nessa concepção, observa-se que há uma necessidade de (re)pensar as estratégias pedagógicas que estão sendo utilizadas para o ensino de línguas estrangeiras atualmente, visto que a formação docente para o educador de línguas se reveste de complexidade, pois inúmeros aspectos estão entrelaçados no processo de ensino-aprendizagem de línguas.

Podemos assim refletir o perfil desejado do professor atual e observar as demandas de um novo modelo de escola, sabemos que a formação docente do professor de línguas é uma proposta de complementação da formação do professor com o intuito de suprir as lacunas e deficiências dessa formação inicial, visando sempre uma qualidade de ensino para os estudantes.

Dessa maneira, são relacionadas possibilidades para o desenvolvimento de competências e habilidades do docente, para que ele esteja preparado para uma nova e constante realidade pedagógica. Sobre formação docente, a autora Volpi menciona:

Numa nova visão da função docente, o professor há de ser um indivíduo consciente de que ele não é o detentor do monopólio do saber, de que o conhecimento, por ser multifacetado, representa um permanente desafio às suas crenças e convicções: de que o ser humano está em constante processo de aprendizagem, e, consequentemente, a sua responsabilidade não se limita à transmissão de informações, mas deve atender a funções sociais mais abrangentes. (VOLPI 2001, p.134) 
Deste modo, os profissionais da educação em formação inicial ou continuada devem buscar um envolvimento no processo de conhecimento das possibilidades para de tornarem transformadores do conhecimento. Conforme os PCN-LE espera-se que o educador de línguas $\mathrm{E}(\mathrm{LE})$ também direcione olhares reflexivos para os aspectos de sua prática docente para a construção do saber. Conforme os Parâmetros Curriculares Nacionais de Língua Estrangeira PCN-LE relatam que:

Tradicionalmente, pensava-se que seria suficiente que o professor fosse exposto a princípios para que sua prática mudasse imediatamente ao abraçar uma nova proposta. Hoje em dia, contudo, sabe-se que o processo é muito mais demorado e complexo, pois a pesquisa indica que, embora os professores frequentemente compreendam princípios teóricos, ao retornarem para a sala de aula, costumam interpretar as inovações em termos de crenças e práticas anteriores. Desse modo, acredita-se, atualmente, que além de se expor o professor aos princípios subjacentes a parâmetros, faz-se necessário seu envolvimento em um processo de reflexão sobre o seu trabalho em sala de aula. Essa reflexão é entendida como o modo mais eficiente para que as práticas em sala de aula sejam questionadas e alteradas, gerando um desenvolvimento contínuo da prática de ensinar língua estrangeira. (BRASIL 1998 p.109)

Diante as novidades criadas pelas tecnologias digitais, o educador tem o desafio de cativar o estudante dentro da sala de aula e instigá-lo para reforçar os conhecimentos em casa. Assim as escolas e os educadores tem tentado se adaptarem a esse novo contexto digital. Com o uso de Ambientes virtuais de aprendizagem, entre outros recursos, a escola tem se aproximado do mundo digital em que os estudantes estão inseridos.

Diante do exposto, vale ressaltar que os recursos tecnológicos para o ensino de Língua Estrangeira (E/LE) sozinhos não serão o suficiente, sempre será necessário saber quais recursos os estudantes utilizam mais, para buscar alternativas para sua aplicação de forma positiva em sala de aula, visando a criação de projetos e intervenções, de acordo com público alvo, e recursos de infraestrutura e recursos didáticos pedagógicos.

Almeida Filho discorre sobre a questão da relevância de uma formação de professores de línguas, mediante a perspectiva da Linguística Aplicada. Segundo o autor: 
[...] aumenta a necessidade de explicitarmos modelos teóricos abrangentes sobre os processos de ensinar e de aprender novas línguas e de o fazermos em uma linguagem acessível ao grande corpo de professores. [...] Acentua-se a necessidade de tornar acessível e articulada a teoria que vimos produzindo em projetos de ensino e aprendizagem de línguas. [...] precisamos prosseguir com $\mathrm{o}$ levantamento da produção nacional dentro dos programas de pósgraduação que se ocupam da pesquisa aplicada. (FILHO 2007, 123124).

O autor está de acordo com a da formação de docentes para o ensino de línguas pela perspectiva da Linguística Aplicada, que trata o fato de promover a reflexão e a associação entre teoria e prática, assim como possibilitar as mudanças necessárias para que o ensino de línguas de fato possa fazer sentido, e contemplar não apenas questões de viés gramatical, mas sim social, isto é trabalhar com as habilidades linguísticas em que o aluno seja capaz de se comunicar e interagir diante da sociedade.

\section{Considerações Finais}

Diante de todos os aspectos abordados nesse artigo, compreende-se a relevância do ensino de Língua Espanhola, tendo em vista o ensino mediado por tecnologias digitais com suas múltiplas possibilidades, que podem auxiliar e promover um ensino de qualidade, com variadas práticas linguístico cultural por meio das tecnologias digitais.

Todas as análises teóricas devem ser aliadas com as práticas realizadas ao longo da formação, conclui se que atualmente os professores estão buscando a cada dia, as tecnologias digitais de acordo com os recursos disponíveis na escola, e esses recursos tecnológicos estão sendo incorporadas nas aulas de E(LE), de acordo com os Parárametros Curriculres Nacionais.

Diante desse panorama percebe se que o ensino de Línguas Estrangeiras não deve se fixar a um padrão tradicional, mas deve acompanhar os avanços tecnológicos em busca de contribuir na formação dos estudantes, para que haja o envolvimento e motivação para compreender a interculturalidade humana e linguística.

Em virtude dos aspectos abordados, acredita-se, que inserção da tecnologia digital no espaço de ensino aprendizagem de Língua Espanhola, pode modificar a forma de práxis atual, 


\section{OO DEVIR EDUCAÇÃO \\ ISSN: 2526-849X}

para que a aquisição e aprendizagem de uma Língua Estrangeira seja algo interessante, eficiente e prazeroso.

\section{Referências}

ALMEIDA FILHO, José Carlos P.de. Linguística aplicada: ensino de línguas \& comunicação.3.ed.São Paulo, SP: Pontes, 2009.

BRASIL, Ministério da Educação, Secretaria da Educação: Parâmetros Curriculares Nacionais - Língua Estrangeira, 3o e 4o ciclos, Brasília, 1998.

KENSKI,V.M. Tecnologias e Ensino Presencial e a Distancia. Campinas, Papirus, 2012.

LEVY, Pierre. Cibercultura. São Paulo - Ed. 34, 1999. 264p. (p. 169-176 recorte).

LLERA, J.A.B.; SÁNCHEZ, P.L. In: Cómo aprender con Internet. Reflexiones Pedagógicas para la práctica Del modelo CAIT. Madrid: Fundación Encuentro, 2003 p. 17-63.

MATEO Martínez, José (1999), La enseñanza universitaria de las lenguas extranjeras. Alicante. Universidad de Alicante Publicaciones.

REDES SOCIAIS: Web 2.0 amplia posibilidades de negocios e revoluciona relações com o mercado. Revista IEL-Interação, ED. Set/Out/Nov.ano 18 207, 2009.

TEDESCO, Juan Carlos. Educación, Tecnologia y Justicia social en la sociedad del conocimento. Revista e-Curriculum, São Paulo, v. 10, np. 03, dez-2012.

VOLPI, Marina T. A formação de professores de língua estrangeira frente aos novos enfoques de sua função docente. $\mathrm{O}$ professor de línguas estrangeiras: construindo a profissão. Pelotas: Educat, p. 125-133, 2001. 